\title{
Study on Social Maturity of Tribal Adolescents in Adilabad District of Telanagana, India
}

\author{
K. Samhitha ${ }^{1 *}$, P. Sreedevi ${ }^{1}$, M. Sarada Devi ${ }^{1}$ and R. Neela Rani ${ }^{2}$ \\ ${ }^{1}$ Department of Human Development and Family Studies, Hyderabad, Professor Jayashankar \\ Telangana State Agricultural University, Telangana, India \\ ${ }^{2}$ Department of Extension Education and Communication Management, Hyderabad, \\ Professor Jayashankar Telangana State Agricultural University, Telangana, India
}

*Corresponding author

\section{A B S T R A C T}

\begin{tabular}{|c|}
\hline Keywords \\
\hline $\begin{array}{l}\text { Social Maturity, Tribal } \\
\text { adolescents, } \\
\text { Interpersonal } \\
\text { adequacy, Social } \\
\text { adequacy, Gender }\end{array}$ \\
\hline Article Info \\
\hline $\begin{array}{l}\text { Accepted: } \\
\text { 15 July } 2019 \\
\text { Available Online: } \\
10 \text { August } 2019\end{array}$ \\
\hline
\end{tabular}

The present research study was undertaken to assess the social maturity of tribal adolescents in Adilabad district. A total sample of 120 adolescents out of which 60 boys and 60 girls in the age range of 13-19 years were selected through purposive random sampling method. Ex-post factor research design was used for the study. A self-designed interview schedule was used to study the socio-demographic characteristics of the respondents. Social maturity of the respondents was assessed by using Rao's Social Maturity Scale. The data was analysed using Frequencies, Percentages, Means, S.D's and ' $t$ '-test. The results revealed that, majority of the tribal adolescents had moderate level of social maturity, very few of them had high level of social maturity and none of them had low level. Early adolescents scored high in almost all the sub components of social maturity like Work Orientation, Enlightened trust, Social Commitment, Social Tolerance, Openness to change, Interpersonal adequacy and Social adequacy except ability to take stress, which was found better among late adolescents. The study also revealed that girls scored significantly higher on the components of cooperation, openness to change and interpersonal adequacy whereas boys scored higher on the ability to take stress component of social maturity.

\section{Introduction}

Adolescence is the crucial stage in which a number of social problems are faced by every individual. These problems arise out of adolescent's adjustment with social groups. Social Maturity is a personal commitment every individual must make as the attitude that will influence his/her daily lives. Individuals can opt for the socially immature attitude of self-centeredness or they can opt for the socially mature attitude of genuine concern for the total well-being of each other. Social maturity is used to measure how well a person fits into the actions and expectations of the society. A person is said to be socially mature if he is skilled, self-directed and has ability to take stress, communicate, cooperate, tolerate and open for change. Social maturity is very essential for proper adjustment in the society 
and is very important aspect on which the future of an adolescent depends. Socially mature individual has the capability to make adjustments with himself and with his environments and circumstances (Singh and Singh, 2015).

Social maturity is a term commonly used in two ways, with reference to the behaviour that conforms to the standards and expectations of the adults and secondly, with reference to the behaviour that is appropriate to the age of the individual under observation.

Thus, Social Maturity permits more detailed perception of the social environment which helps adolescents to influence the social circumstances and develop stable patterns of social behaviour.

An immature adolescent creates problems with his family, peer group and society so it is critical for an adolescent to acquire more mature pattern of behaviour to be accepted by society.

Research studies revealed that the tribal students are backward in social activities and social participation as compared to their counterparts i.e., non-tribal students due to far from the mainstream of the society (Pradhan, 2010 and Dubey, 2010). Most of the tribal adolescents were suffering from various psychosocial problems like inferiority complex especially girls (Swarnalata Das et al., 2016). Hence, an attempt was made to study the social maturity among tribal adolescents with the following objectives:

\section{Objectives of the study}

To study the levels of social maturity among tribal adolescents

To find out the age and gender differences in social maturity

\section{Materials and Methods}

Based upon the nature of the research problem and objectives of the present study, Ex-post factor research design was used. 120 tribal adolescents ( 60 boys and 60 girls) who were in the age range of 13-19 years were purposively selected. Interview schedule was designed by the investigator for the study which includes general profile of the tribal adolescents. Rao's social maturity scale developed by Dr. Nalini Rao was used to find out the social maturity of the respondents. The scale has three major components and 90 items under nine dimensions-Work Orientation, Self-Direction, Ability to take Stress, Interpersonal Adequacy by communicable, Enlightened Trust, Cooperation and Social Adequacy by social Commitment, social Tolerance and Openness to change.

The response options available for the items are: Strongly Agree, Agree, Neutral, Disagree and Strongly Disagree with scores of 5, 4, 3. 2 and 1 for positive items and 1,2,3,4 and 5 for negative items respectively. The scores of a respondent on 3 sub-scales of the social maturity scale collectively gives the Composite Social Maturity Score.

\section{Results and Discussion}

\section{General profile of the respondents}

An equal number of boys and girls in the age range of 13-15 years and 17-19 years were selected for the study. According to the demographic data of the tribal adolescents nearly half of tribal adolescents were first borns followed by $2^{\text {nd }}$ borns, belonged to nuclear families, followed by extended families and only few were from joint families. More than half of the respondents were perusing their degree, few of them were in $10^{\text {th }}$ class followed by $9^{\text {th }}$ class and $8^{\text {th }}$ class. 
Half of the respondents were studying in Government schools and colleges and the remaining half in private institutions.

More than forty percent (42\%) of their fathers studied up to primary school followed by Secondary school, few of them were illiterates and meagre percent were graduates and postgraduates. About mother's education, more than $1 / 3^{\text {rd }}$ of their mothers $(35 \%)$ are illiterates followed by primary and secondary schooling. Very few mothers studied up to intermediate followed by graduation and post-graduation degree. Similarly, Swachita (2015) found that majority of the mothers of tribal secondary school students were found to be illiterates.

Out of the total sample, more than half $(56 \%)$ of the fathers had Agriculture as their major occupation, whereas few of them were working in government sector or private sector, had their own businesses, working in different caste related occupations and very few were unemployed. Similar results were found in a study conducted by Swachita (2015) that $82 \%$ of the fathers in a tribal community perceive Agriculture as main occupation.

Similarly, thirty nine percent of the mothers had agriculture as their main occupation followed by wage labour. Few of them were house wives and working in caste related occupations like dhobi work, selling milk, etc. Very few were working in government sector and private sector or had their own businesses.

In the sub categories of personal adequacy component, i.e., work orientation, selfdirection and ability to take stress, majority of the tribal adolescents had moderate levels. It means that, majority of the tribal adolescents were able to make adjustments within their self, putting efforts to reach personal goals, learning to come out of their comfort zones. They were willing to put efforts consistently in completing works that takes longer time, able to take decisions and execute things independently and had clarity in life goals. This might be due to guidance and encouragement from their parents to take individual responsibility for their behaviours, independent decision making and being initiative.

But to some extent, they had difficulty in making adjustments within self like balancing works based on priorities and relying on internal locus of control like hard work for their success and failures rather than on luck and fate. They also had difficulty to regulate and control their self from difficult situations like facing criticism which upsets them. They were also easily stressed out and get hurt on criticism, were unable to control anger and quickly involved in arguments. Similar findings were observed in a study conducted by Reena and Sam (2017) in which half of the adolescents $(50 \%)$ had moderate level of stress.

In the sub categories of interpersonal adequacy i.e., communication, enlightened trust and cooperation, majority were in moderate levels followed by high levels. None of them had low level of communication but meagre percent of them had low levels in enlightened trust and cooperation. It means that, majority of the adolescents were able to make adjustments within their environments. They were able to make adjustments in their communication patterns with different people in their environment with more clarity in ideas and thoughts.

They had trust on people in their familiar settings like teachers, parents and close friends, had empathy towards people who are less fortunate and willing to work with their classmates and friends by accepting the individual differences and limitations. But they also have difficulty in maintaining 
interpersonal skills like working in groups who are not much familiar to them, making firm decisions on whom to trust and how much to trust as they are egocentric in their thoughts hence not willing to cooperate in taking up the responsibilities which are not matching to their as personal interest.

In the sub categories of social adequacy component i.e., social tolerance and openness to change, almost equal percentages of them were in high and moderate levels. It means that, they were able to make adjustments with their social circumstances like being selftolerant towards people by accepting the subcultural differences in their ideologies, value systems and belief systems and were open minded towards issues related to gender equalities. In Social commitment, majority had moderate level followed by high level. It indicates that, to some extent they were willing to make adjustments with self and to contribute for the betterment of society by helping the needy and work for future generations. At the same time, they were intolerant with the ideologies of others that are conflicting with their personal views, very few of them had rigid ideology towards gender stereotypical occupational patterns (e.g.: Men shouldn't be trained for caretakers' jobs, women shouldn't be trained for all the jobs).

The above graph depicts that in the social adequacy component, half of them had high level and remaining half had moderate level. It means that, they were well adjusted to the social circumstances and were able to interact with others. In the sub-components of social maturity i.e. personal adequacy and Interpersonal adequacy, majority of the respondents were in moderate level and very few were in high level. It means that, majority were to some extent they were adjusting himself/herself towards to their immediate social environment but at the same time they had difficulty in making adjustments with their self as well as with people in their environment when it is disagreed with their typical interests and comfort levels. Similar results were found in a study conducted by Hood (2014) who found that, on the dimension of personal adequacy and social adequacy, majority of rural, urban and tribal respondents scores lied in average (moderate) level but in interpersonal adequacy majority were in high level of social maturity.

With regard to the adolescent's overall social maturity level, only few (23\%) of them had high level it means they were good at making adjustments within self, with the individuals in their social environment and with social circumstances and majority of them $(77 \%)$ of the respondents were in moderate level and none of the adolescents had low level of social maturity. It means that, to some extent majority of the tribal adolescents were able to make adjustments within themselves in terms of coming out of the comfort zones and work for personal goals and making adjustments with people in their environments and also towards difficult circumstances which are challenging in life, turning from ego centric to socio centric behaviours by modifying ones goals in order to work with others, in considering views and ideologies of others.

It was also observed that they had very rigid ideology towards religion and gender stereotypical roles. Similar results were found in a study conducted by Arora (2016) who revealed that, major population of rural adolescent boys and girls were in the category of moderate maturity levels of social maturity. Wartynghah and Sngewbhalang (2013) also found that, most of the urban secondary school students had average social maturity followed by above average category. Rani and Prabha (2007) also found in their study that, nearly half of the urban adolescents had moderate level followed by low and high levels of social maturity (Table 1). 
Table.1 Distribution of tribal adolescents based on components of Social Maturity $(n=120)$

\begin{tabular}{|c|l|c|c|c|c|c|c|}
\hline Sl. No & Sub-Category Details & \multicolumn{2}{|c|}{ Low } & \multicolumn{3}{|c|}{ Moderate } & \multicolumn{2}{c|}{ High } \\
\hline & & $\mathbf{n}$ & $\mathbf{\%}$ & $\mathbf{N}$ & $\mathbf{\%}$ & $\mathbf{n}$ & $\%$ \\
\hline $\mathbf{1 .}$ & Work Orientation & 4 & 3 & 89 & 74 & 27 & 23 \\
\hline $\mathbf{2 .}$ & Self-Direction & 6 & 5 & 73 & 61 & 41 & 34 \\
\hline $\mathbf{3 .}$ & Ability to take stress & 46 & 38 & 68 & 57 & 6 & 5 \\
\hline & Personal Adequacy & 1 & 2 & 106 & 88 & 13 & 10 \\
\hline $\mathbf{4 .}$ & Communication & 0 & 0 & 82 & 68 & 38 & 32 \\
\hline $\mathbf{5 .}$ & Enlightened Trust & 10 & 8 & 93 & 78 & 17 & 14 \\
\hline 6. & Cooperation & 8 & 7 & 92 & 76 & 20 & 17 \\
\hline & Interpersonal Adequacy & 0 & 0 & 102 & 85 & 18 & 15 \\
\hline 7. & Social Commitment & 0 & 0 & 83 & 69 & 37 & 31 \\
\hline 8. & Social Tolerance & 0 & 0 & 64 & 53 & 56 & 47 \\
\hline 9. & Openness to change & 3 & 2 & 55 & 46 & 62 & 52 \\
\hline & Social Adequacy & 0 & 0 & 60 & 50 & 60 & 50 \\
\hline
\end{tabular}

Table.2 Mean differences in the social maturity of the sample under different age groups

\begin{tabular}{|c|c|c|c|c|c|c|c|}
\hline \multirow[t]{2}{*}{$\begin{array}{l}\text { S. } \\
\text { No }\end{array}$} & \multirow[t]{2}{*}{$\begin{array}{l}\text { Components of Social } \\
\text { Maturity }\end{array}$} & \multicolumn{2}{|c|}{$\begin{array}{l}\text { 13-15 years } \\
\text { (Early } \\
\text { Adolescents) }\end{array}$} & \multicolumn{2}{|c|}{$\begin{array}{l}\text { 17-19 years (Late } \\
\text { Adolescents) }\end{array}$} & \multirow[b]{2}{*}{ 't } & \multirow[b]{2}{*}{ P Value } \\
\hline & & Mean & S. D & Mean & S. D & & \\
\hline \multicolumn{8}{|c|}{ Personal Adequacy } \\
\hline 1 & Work Orientation & 34.13 & 5.03 & 31.55 & 5.24 & 2.76 & $0.003 * *$ \\
\hline 2 & Self-Direction & 28.53 & 5.14 & 27.87 & 4.04 & 0.79 & 0.22 \\
\hline \multirow[t]{2}{*}{3} & Ability to take stress & 17.3 & 3.29 & 18.91 & 3.88 & 2.46 & $0.01 *$ \\
\hline & Total & 79.97 & 10.01 & 78.33 & 10.70 & 0.86 & 0.19 \\
\hline \multicolumn{8}{|c|}{ Interpersonal Adequacy } \\
\hline 4 & Communication & 35.13 & 5.64 & 33.85 & 4.39 & 1.4 & 0.08 \\
\hline 5 & Enlightened trust & 26.83 & 3.96 & 25.57 & 3.01 & 1.97 & $0.03 *$ \\
\hline \multirow[t]{2}{*}{6} & Cooperation & 21.87 & 3.14 & 21.52 & 3.36 & 0.59 & 0.29 \\
\hline & Total & 83.83 & 8.51 & 80.93 & 7.07 & 2.03 & $0.02 *$ \\
\hline \multicolumn{8}{|c|}{ Social Adequacy } \\
\hline 7 & Social Commitment & 35.53 & 3.46 & 33.52 & 3.35 & 3.24 & $0.001 * *$ \\
\hline 8 & Social Tolerance & 30.18 & 2.99 & 29.9 & 3.94 & 0.44 & $0.03 *$ \\
\hline \multirow[t]{3}{*}{9} & Openness to change & 24.97 & 2.92 & 23.47 & 3.61 & 2.51 & $0.001 * *$ \\
\hline & Total & 90.68 & 6.23 & 86.83 & 9.18 & 2.65 & $0.004 * *$ \\
\hline & Overall social maturity & 254.48 & 19.6 & 246.15 & 23.46 & 2.11 & $0.02 *$ \\
\hline
\end{tabular}

$* * \mathrm{P}<0.01$ level of significance, $* \mathrm{P}<0.05$ level of significance. 
Table.3 Gender differences in the social maturity of the respondents

\begin{tabular}{|c|c|c|c|c|c|c|c|}
\hline \multirow{2}{*}{$\begin{array}{l}\text { S. } \\
\text { No }\end{array}$} & \multirow{2}{*}{$\begin{array}{l}\text { Components of } \\
\text { Social Maturity }\end{array}$} & \multicolumn{2}{|c|}{ Boys } & \multicolumn{3}{|c|}{ Girls } & \multirow[b]{2}{*}{ P Value } \\
\hline & & Mean & SD & Mean & SD & ' $t$ ' & \\
\hline \multicolumn{8}{|c|}{ Personal Adequacy } \\
\hline 1 & Work Orientation & 32.23 & 4.72 & 33.45 & 5.75 & 1.27 & 0.10 \\
\hline 2 & Self-Direction & 27.55 & 4.94 & 28.85 & 4.20 & 1.55 & 0.06 \\
\hline \multirow[t]{2}{*}{3} & Ability to take stress & 19.01 & 3.47 & 17.2 & 3.67 & 2.79 & $0.003 * *$ \\
\hline & Total & 78.8 & 10.05 & 79.5 & 10.71 & 0.37 & 0.36 \\
\hline \multicolumn{8}{|c|}{ Interpersonal Adequacy } \\
\hline 4 & Communication & 34.18 & 5.55 & 34.8 & 4.58 & 0.66 & 0.25 \\
\hline 5 & Enlightened trust & 26 & 3.60 & 26.4 & 3.54 & 0.61 & 0.27 \\
\hline \multirow[t]{2}{*}{6} & Cooperation & 20.7 & 3.24 & 22.68 & 2.96 & 3.5 & $0.0003 * *$ \\
\hline & Total & 80.88 & 7.84 & 83.88 & 7.79 & 2.1 & $0.02 *$ \\
\hline \multicolumn{8}{|c|}{ Social Adequacy } \\
\hline 7 & Social Commitment & 34.55 & 3.80 & 34.5 & 3.29 & 0.07 & 0.08 \\
\hline 8 & Social Tolerance & 29.57 & 3.78 & 30.52 & 3.12 & 1.5 & 0.07 \\
\hline \multirow[t]{3}{*}{9} & Openness to change & 23.5 & 3.64 & 24.93 & 2.88 & 2.39 & $0.01 * *$ \\
\hline & Total & 87.62 & 9.09 & 89.95 & 6.70 & 1.6 & 0.06 \\
\hline & $\begin{array}{l}\text { Overall social } \\
\text { maturity }\end{array}$ & 247.33 & 22.25 & 253.33 & 21.35 & 1.52 & 0.07 \\
\hline
\end{tabular}

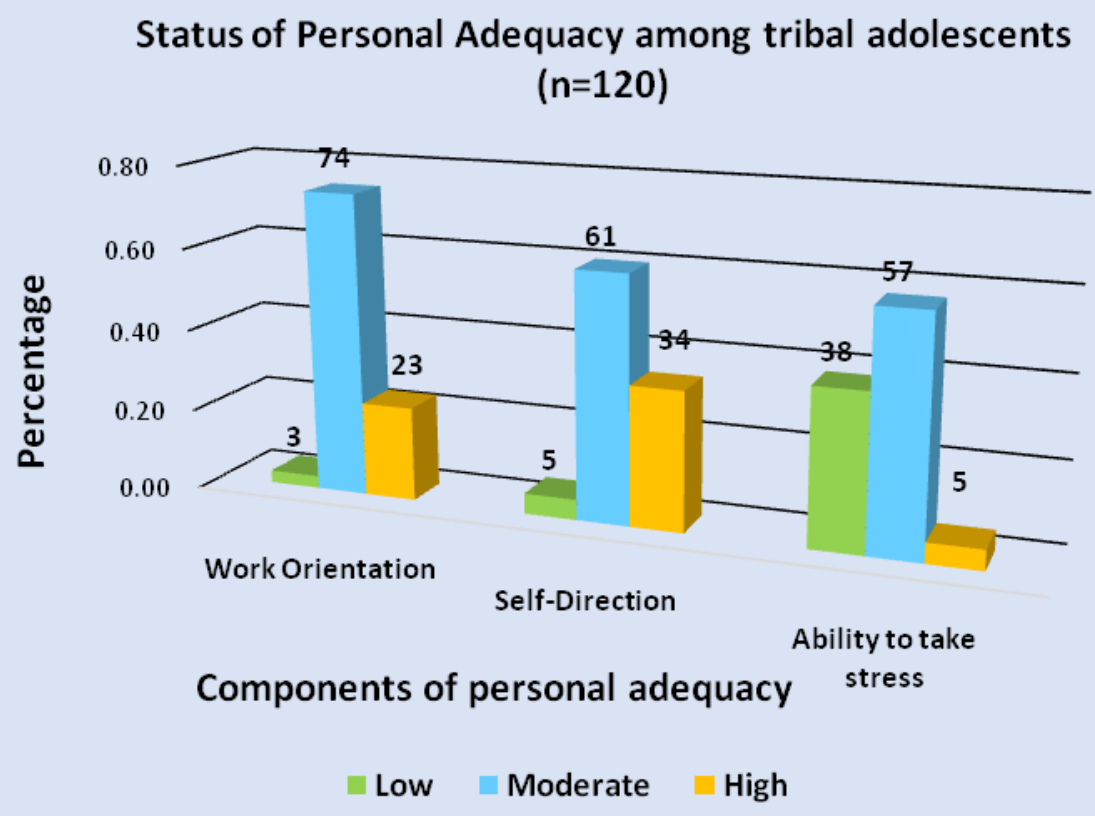



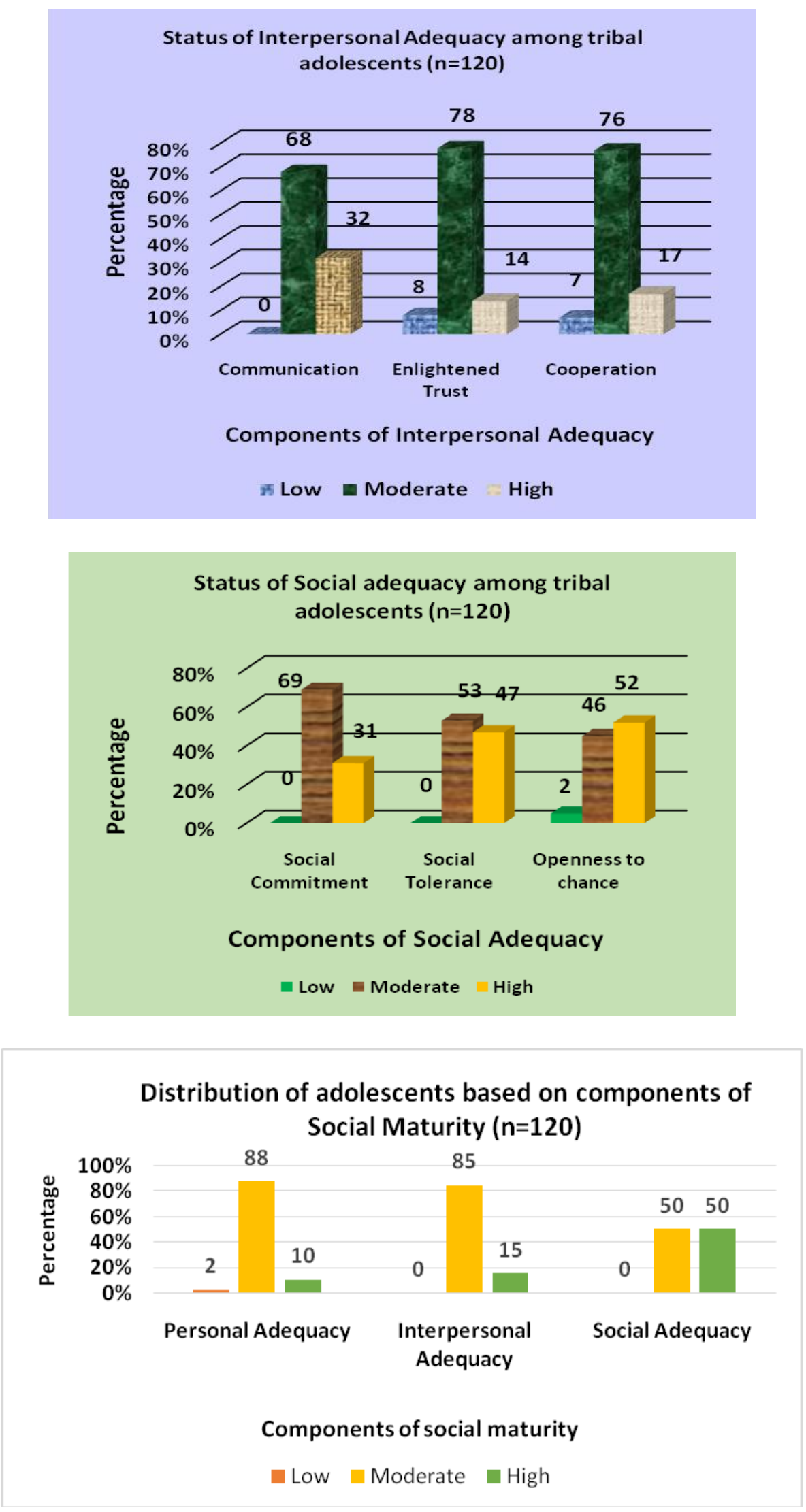


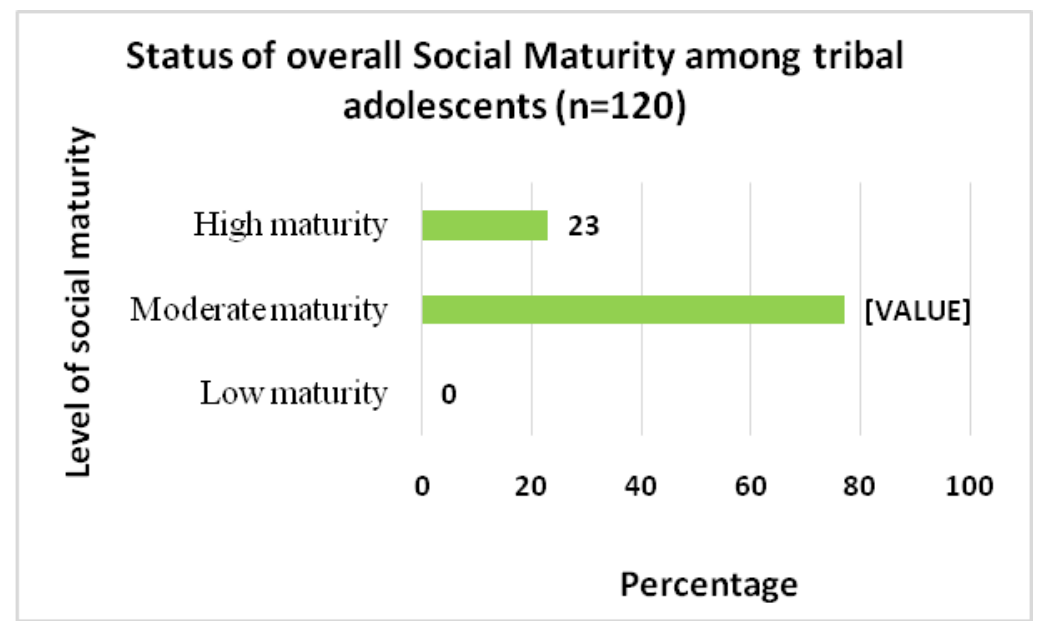

It is evident from the above table 2 that, significant differences were observed in early and late adolescents in the components of Work orientation, Enlightened trust, Social commitment, Social tolerance, Openness to change, Interpersonal Adequacy, Social adequacy and overall social maturity in which, early adolescents secured higher mean scores than late adolescents. It means that, early adolescents were accepting more the existing ideologies and value systems of their society, had more trust and depend more on the people in their familiar setting, willing to put efforts to take up work beyond their personal interest and choice compared to late adolescents. In a study conducted by Flanagan and Stout (2010) found that, late adolescents had significantly lower levels of trust on others than early adolescents.

This might be due to the reason that, early adolescents were provided with more guidance and support by parents in completing tasks and had limited social interactions that to with familiar people when compared to late adolescents. In contrast, late adolescents were exposed to diversified people in unfamiliar setting and are expected to take decisions and act independently, expected to make adjustments beyond their personal interests which is a psycho social crisis for them hence scored less in social maturity levels than early adolescents.
It is also important to note that the late adolescents had greater ability to take stress when compared to their counterparts this might be due to the reason that, as an individual becomes older there will be a progression in cognitive abilities and opportunities to deal with different social environments helps them to handle and cope up with challenging and stressful situations effectively.

There were no significant differences were found between early and late adolescents in the components of Self-Direction, Communication, Cooperation and Personal Adequacy. Which means both early and late adolescents were on par with each other in the above components. This might be due to the reason that, early and late adolescents exhibited same behaviours in the abovementioned components in spite of age advancement.

The above table 3 depicts the significant gender differences between boys and girls. In the components of interpersonal adequacy like cooperation and openness to change girls had higher mean scores than boys whereas in the personal adequacy component of ability to take stress boys had higher mean scores when compared to girls. The results were supported by the study conducted by Rani and Prabha (2007) who found that, girls had higher 
interpersonal adequacy than boys. It indicates that, girls were better in terms interpersonal skills like being cooperative others and willing to adapt to the changes that are taking place in the social world. The reason could be due to differences in gender role socialization in which girls were oriented and expected to be more flexible, open, adjust, accept and respect others ideologies and views when compared to their counter parts. Boys scored more on personal skills like how to handle stress when compared to girls. Contradictory results were found in a study conducted by Pooja (2008) who found that, female senior secondary school students from urban were better self-directed and had more ability to take stress than their male counter parts.

There were no significant differences found in the components of work orientation, selfdirection, communication, enlightened trust, social commitment, social tolerance, personal adequacy, social adequacy and overall social maturity which indicates both boys and girls were on par with each other in terms of persistency in completion of work, taking independent decisions, making adjustments in communicating patterns, using discretions in trusting different people, making contributions for the society, tolerating prescribed value systems and differences in the society. The reason could be that, both boys and girls were similarly socialised on the above.

From the above study it can be concluded that, only few tribal adolescents were high in social maturity whereas majority of the adolescents had moderate levels of social maturity. Social adequacy is more when compared to personal and inter personal adequacy among tribal adolescents. Ability to take stress, trust on others, cooperation and openness to change was found to be low when compared to other components of social maturity. Early adolescents were better adjusted with their self, with people in their environment and to social circumstances when compared to late adolescents. Late adolescents had better ability to take up stress when compared to early adolescents. Girls were better in interpersonal skills like being cooperative with others, more flexible and open minded in accepting change in rigid/ conventional ideologies when compared to boys whereas boys were better in terms of ability to take stress and challenges in life when compared to girls.

Socially maturated adolescent turns to become a socially matured adult thus establishes more matured relationships with peers, friends and people around thus achieves socially responsible behaviour, develops intellectual skills and concepts necessary for civil competence and achieves a more independent behaviour.

The adolescents need improvements in the personal adjustment skills, and interpersonal adjustment skills. Girls need to learn the strategies to handle their stress and boys needs to be more oriented to exhibit cooperative behaviours in their social environments. Parents must practice and teach the adolescents about broad ideologies, gender equality, must monitor the adjustment behaviours of their adolescents and provide sensitive guidance and care.

Personnel working with adolescents must plan intervention programmes for the betterment of social status of the tribal adolescents. Adolescents should come out of their egocentric adjustment patterns and conventional ideas. They should move to towards sociocentrism and develop positive thinking, personal and interpersonal skills so that they could function effectively in the society. They should be trained in life-skills which would help them to handle and cope up with the stressful situations. 


\section{References}

Constance A. Flanagan and Michael Stout, 2010. Developmental Patterns of Social Trust between Early and Late Adolescence: Age and School Climate Effects. Journal of Research on Adolescents. Sep 1; 20(3): 748-773.

Garrett Henry, Wood worth RS, 2008. Statistics in Psychology and Education, Surjeet Publications Ltd, New Delhi.

Kalyanidevi, T. and Prathima Chaitanya, N.2008. Social maturity of scheduled tribes' adolescents, Psycho-lingua, 38 (2), 147-151, Agra: Psycho linguistics association of India.

Pooja, 2008. Impact of values on social maturity of senior school students. Unpublished M.Ed. Dissertation, Punjab University, Chandigarh.

Pradhan, K. C. 2010. Getting the Secluded into social-mainstream through micro projects. Dalits and Tribes of India
(131-150). New Delhi: Mittal Publication.

Samridhi Arora 2016. Perceived Parental Encouragement as Related to Social Maturity of Adolescence in Jammu. International Journal of Social Sciences, Arts \& Humanities, 4(1), pp 30-32. www.crdeep.com/ijssah.

Swachita. P \& Devi, S. M, 2015. Impact of Anandam intervention on overall development of tribal Infants. Dissertation, Professor Jayashankar Telangana state agricultural university, Hyderabad. Wartynghah \& Sngewbhalang 2013. A study on Social maturity of secondary school students in Shillong town. http://hdl.handle.net/10603/169860.

Zaki Akhtar 2012. Anxiety and adjustment pattern among tribal and non-tribal students. Indian Journal of Health and Wellbeing. 3(3), 723-725.

\section{How to cite this article:}

Samhitha, K., P. Sreedevi, M. Sarada Devi and Neela Rani, R. 2019. Study on Social Maturity of Tribal Adolescents in Adilabad District of Telanagana, India. Int.J.Curr.Microbiol.App.Sci. 8(08): 1890-1899. doi: https://doi.org/10.20546/ijcmas.2019.808.222 